\title{
Effect of a training program for primary care physicians on the optimization of beta-blocker treatment in elderly patients with heart failure
}

\author{
Efecto de un programa de formación en atención primaria sobre la optimización del \\ tratamiento con bloqueadores beta en pacientes ancianos con insuficiencia cardiaca
}

Manuel Anguita Sánchez, Manuel Jiménez-Navarro, Marisa Crespo, Luis AlonsoPulpón, Eduardo de Teresa, Alfonso Castro-Beiras, Eulàlia Roig, Remei Artigas, Antonio Zapata, Ignacio López de Ulibarri, Javier Muñiz, On behalf of the OBELICA study researchers

\begin{abstract}
Introduction and objectives. Underuse of beta-blockers may contribute to elevated mortality in chronic heart failure. The aim of this study was to determine whether a specific interventional training program for primary care physicians would help optimize the use of beta-blockers in elderly chronic heart failure patients.

Methods. This randomized comparative study included 627 patients aged 70 years or more who were discharged consecutively from 53 Spanish hospitals with a principal diagnosis of chronic heart failure. In total, 292 health-care centers in the catchment areas of these hospitals were randomly assigned to two groups: one group of 146 centers carried out an interventional training program on beta-blocker use for primary care physicians belonging to the centers assigned to training, and 146 centers served as a control group. The main outcome variable was the percentage of patients who were receiving a beta-blocker at the maximum or maximum tolerated dose 3 months after hospital discharge.

Results. The patients' mean age was $78 \pm 5$ years and $42 \%$ were women. There was no difference between the groups in demographic characteristics, clinical care, or treatment at discharge. The percentage of patients who received betablockers at the maximum tolerated dose 3 months after discharge was greater in the training group (49\% vs. 38\%; $P=.014)$. Being treated in the training group was an independent predictor of receiving a beta-blocker at the MTD (odds ratio=2.46; 95\% confidence interval, 1.29-4.69; $P<.001$ ).

Conclusions. Implementation of an interventional training program on beta-blocker treatment for primary care physicians improved the use of these medications in elderly chronic heart failure patients.

\section{Resumen}

Introducción y objetivos. La infrautilización de bloqueadores beta puede influir en la elevada mortalidad de la insuficiencia cardiaca. El objetivo de nuestro estudio es evaluar si un programa específico de intervención sobre médicos de atención primaria permite optimizar el uso de bloqueadores beta en pacientes ancianos con insuficiencia cardiaca.

Métodos. Se diseñó un estudio aleatorizado y comparativo en el que se incluyó a 627 pacientes de 70 o más años, dados de alta de forma consecutiva con el diagnóstico principal de insuficiencia cardiaca en 53 hospitales españoles. Se realizó una asignación aleatoria de los 292 centros de salud de las áreas de esos hospitales a dos grupos (formación, 146 centros, y control, 146 centros), para impartir un programa de intervención y formación sobre bloqueadores beta a los médicos pertenecientes a los centros del grupo formación. La variable principal fue el porcentaje de pacientes que recibían la dosis máxima o máxima tolerada de bloqueadores beta a los 3 meses del alta. Resultados. La edad de los pacientes era de $78 \pm 5$ años; el $42 \%$ eran mujeres. No hubo diferencias entre ambos grupos en sus características demográficas, clínicas o en el tratamiento al alta. El porcentaje de pacientes que recibían la dosis máxima tolerada de bloqueadores beta a los 3 meses del alta fue mayor en el grupo formación (el 49 frente al $38 \% ; \mathrm{p}=0,014)$; pertenecer al grupo formación fue predictor independiente de recibir la dosis máxima tolerada de bloqueadores beta (odds ratio = 2,46; intervalo de confianza del 95\%, 1,29-4,69; $\mathrm{p}<0,001$ ).

Conclusiones. Un programa de formación sobre bloqueadores beta en atención primaria mejora su uso en pacientes ancianos con insuficiencia cardiaca.
\end{abstract}

\section{Key words}

Beta-blockers; Heart failure; Intervention program 
Palabras clave

Bloqueadores beta; Insuficiencia cardiaca; Programa de intervención

Abbreviations

ACE, angiotensin converting enzyme; ARB-II, angiotensin II receptor blockers; CHF, chronic heart failure

\section{Introduction}

Heart failure is a very important medical problem. Recent data from a demographic study in Spain indicate that the prevalence of heart failure is $7 \%$ in persons older than 45 years of age. ${ }^{1}$ The problem becomes more serious as patients become older, and the prognosis worsens in elderly patients. ${ }^{2,3}$ The prognosis for patients with chronic heart failure (CHF) has improved over recent decades, with the development and introduction of drugs such as angiotensin converting enzyme (ACE) inhibitors, angiotensin II receptor blockers (ARB-II), aldosterone antagonists and beta-blockers. The use of these medications has led to an improvement in the prognosis for these patients, ${ }^{4-6}$ though this improvement has only resulted in a small favorable effect in the general population of CHF patients. ${ }^{7}$ One reason for this lower positive effect of the treatment in the general population is related with underuse in daily clinical practice, a problem that seems to be more aggravated with beta-blockers. ${ }^{8}$ Several reasons exist for this underuse of beta-blockers in CHF patients, including lack of information about their effect in older patients, as the age of the patients included in the classical clinical trials of beta-blockers is only around 61 years. ${ }^{9-12}$ Until publication of the SENIORS study, no specific information was available about the utility of beta-blockers in patients older than 70 years of age. ${ }^{13}$ Additionally, the optimization of pharmacologic treatment of CHF is known to be less correct when administered by primary care physicians and other specialists than it is when controlled by the cardiologists themselves, ${ }^{14,15}$ particularly that related with beta-blocker therapy. ${ }^{16}$ Accordingly, we attempted to determine the efficacy of a specific training program for primary care physicians about beta-blockers in elderly CHF patients.

\section{Methods}

\section{General Study Characteristics. Inclusion Criteria}

We designed a multicenter, randomized, comparative open study to compare the effect of a training program for primary care physicians on the use of beta-blockers in CHF patients aged 70 years or over. The primary care physicians were randomly assigned either to follow the training program (interventional group) or not to follow it (control group). The primary outcome efficacy variable was the percentage of patients who were receiving the optimal dose of beta-blockers after 3 months of follow-up. The optimal dose was considered to be the maximum dose $(10 \mathrm{mg} / \mathrm{d}$ for bisoprolol and nebivolol, and $50 \mathrm{mg} / \mathrm{d}$ for carvedilol) or the maximum dose tolerated by the patient due to the symptomatic presence of hypotension or bradycardia. Secondary endpoints included: a) the incidence of admissions for cardiovascular causes; b) the maximum dose of beta-blocker reached; and c) tolerance of the beta-blocker (side effects). The study was coordinated and controlled by the Spanish Society of Cardiology Research Agency, and undertaken with the aid of an unconditional grant from Menarini. The study included patients of both sexes, aged $\geq 70$ years, and with a diagnosis of heart failure according to the European Society of Cardiology criteria, independently of their left ventricular ejection fraction. The exclusion criteria were: patients younger than 70 years of age, an absolute contraindication for beta-blockers (bronchial hyperreactivity, important bradycardia, second or third degree atrioventricular block), patients who were already taking the optimal dose of beta-blockers or whom the physician considered would require a close follow-up in the specialist clinic or the heart failure clinic, patients with heart failure due to important valvular disorders, patients who were already participating in a clinical trial or patients who refused to sign the informed consent form.

\section{Sample Size}

Accepting an alpha error of .05, the sample size was calculated to be 630 patients (315 in each group), providing greater than $85 \%$ power in bilateral contrast to detect a difference $\geq 9 \%$ between the 2 groups in the main outcome efficacy variable. We assumed a $25 \%$ proportion of adequate beta-blocker use among the patients seen by primary care physicians who did not participate in the training program. 


\section{Study Design}

The study involved 53 hospitals with their associated health centers from all over Spain (11 in Andalusia, 2 in Asturias, 2 in the Balearic Isles, 7 in the Community of Valencia, 4 in the Canary Isles, 3 in CastileLa Mancha, 4 in Castile-Leon, 7 in Catalonia, 2 in Extremadura, 3 in Galicia, 5 in Madrid, and 3 in the Basque Country). The participating hospitals were not selected randomly, but rather those centers that accepted to participate in the study out of the 70 initially invited were included. The primary care physicians in each participating center were blindly assigned randomly to the training program or the control group by the central co-coordinating center. One group of primary care physicians received the training program on the use of beta-blockers in patients with heart failure and the other did not. The intervention included written educational material, based on the recommendations of the European Society of Cardiology (ESC) and American Heart Association (AHA) guidelines on heart failure ${ }^{4,5}$ and an interactive meeting between the lead researcher of each center and the primary care physicians selected, at which the training material was presented and practical aspects of beta-blocker therapy were discussed. Each participating center included 14 patients: the first 7 consecutive patients to be seen by the primary care physicians who had received the training program and the first 7 patients seen by the primary care physicians randomly assigned to the control group. The recruitment of the patients took place over an 8month period. All the patients were seen again after 3 months in the cardiology or heart failure clinic. This second appointment was with a different physician from the one who performed the initial evaluation at the inclusion visit and who was unaware of the group to which the patient's physician belonged. At each visit records were made of demographic, clinical and therapeutic data (Tables 1-3). At the final visit, after 3 months, data were also collected on all the events arising since inclusion.

\section{Statistical Analysis}

Analysis of the main outcome variable was done by comparison of percentages between the 2 groups using the $\chi^{2}$ test for qualitative variables and the Student $t$ test for quantitative variables. A step-by-step logistic regression model was used to evaluate the effect of being seen by physicians in the intervention group or in the control group on the probability of receiving optimal beta-blocker treatment, adjusted for potential confounding factors identified in the univariate analysis and for variables with known clinical relevance. As well as the variables that proved significant in the univariate analysis, the logistic regression model included: age, sex, duration of the heart failure, previous admissions for heart failure, functional class, systolic blood pressure, ejection fraction, type of heart failure (with preserved or depressed systolic function), dose of ACE inhibitors, dose of ARB-II, dose of beta-blockers, treatment with digoxin and treatment with aldosterone antagonists. Analysis of the secondary outcome measures was done with the Student $t$ test.

\section{Ethical and Legal Considerations}

The study was approved by a clinical research ethics committee (Hospital General de Alicante), and complied with the Spanish law on clinical trials. The participants were all required to provide informed consent. Current Spanish legislation was also followed concerning data protection.

\section{Results}

Baseline Characteristics of the Groups The study included 627 patients, 318 randomized to the training group physicians and 309 to the control group physicians. Nine patients were lost during the follow-up, so the final analysis comprised the data on 618 patients (312 in the training group and 306 in the control group). Table 1 shows the clinical characteristics of the patients at their initial admission and the most important points in the history; no significant differences were found between the two groups. The mean age of the patients was almost 78 years in both groups; just over $40 \%$ of the patients were women. There was a high prevalence of hypertension and diabetes mellitus, and about $40 \%$ of the patients in both groups had had a previous myocardial infarction (Table 1). The ejection fraction was $42(13 \%)$ in the intervention group and $42(14 \%)$ in the control group. CHF with a depressed systolic function (ejection fraction $<45 \%$ ) was present in $61 \%$ of the intervention group patients and in $60 \%$ of the control group. The ejection fraction was $<35 \%$ in $47 \%$ of both groups. There were no differences between the groups during the initial admission in the concentrations of natriuretic peptides, hemoglobin or serum creatinine (Table 1). 
Table 1. Characteristics of the Patients in the Training Group and the Control Group at the Initial Visit

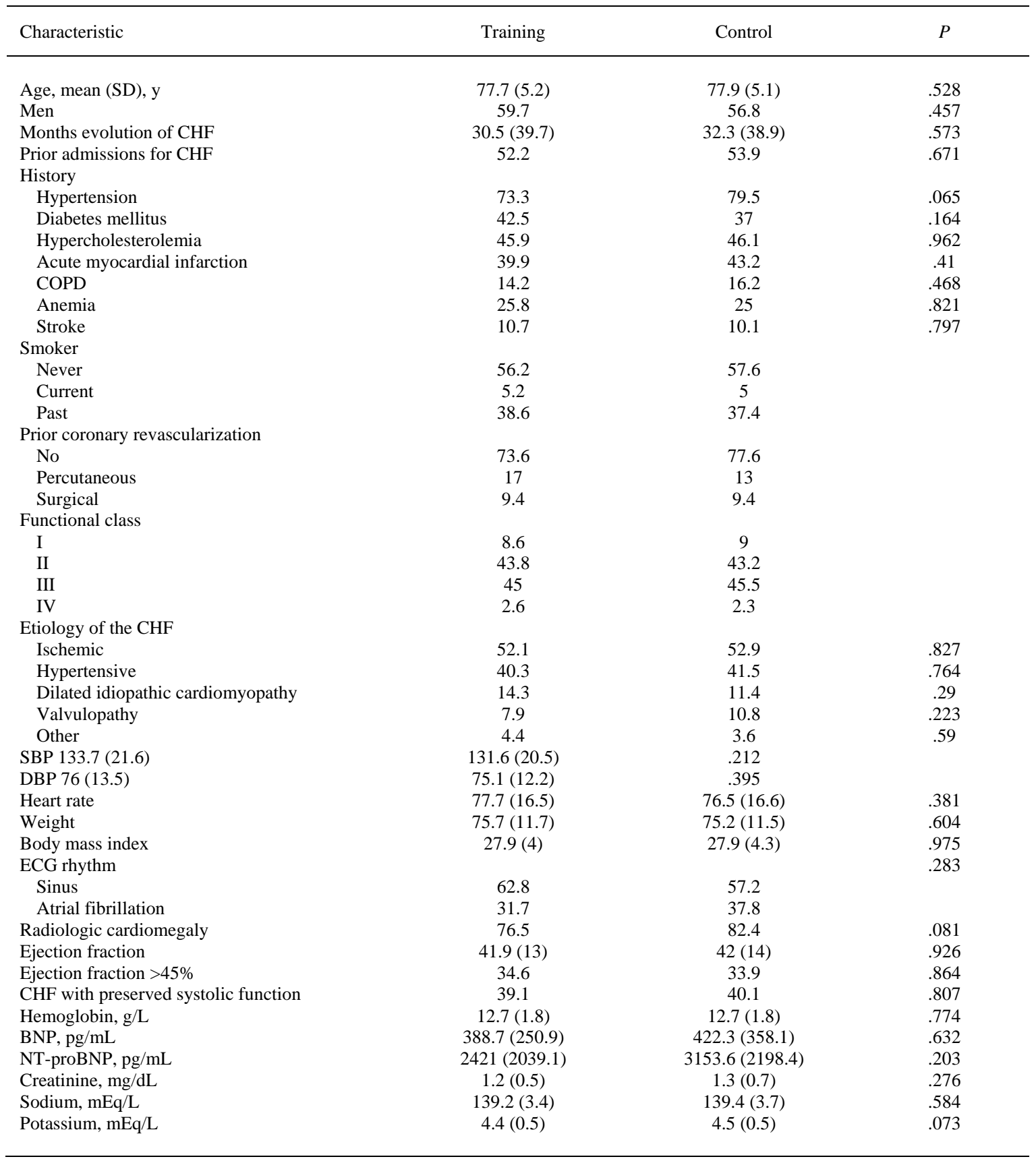

BBNP indicates brain natriuretic peptide; COPD, chronic obstructive pulmonary disease; CHF, chronic heart failure; DBP, diastolic blood pressure; ECG, echocardiogram; SBP, systolic blood pressure.

Results are expressed in percentages (quantitative variables) and mean (standard deviation) (qualitative variables.

Nor were there differences between the groups in the pharmacologic treatment on discharge, as can be seen in Table 2, except that in the control group more patients received ACE inhibitors (64\% vs 57\%) and fewer ARB-II (25\% vs 32\%). Nonetheless, the percentage of patients who received ACE inhibitors and/or ARB-II was similar in both groups (88\%) (Table 2) 
Table 2. Pharmacologic Treatment of the Patients in the Training Group and the Control Group at the Initial Visit and the Final Visit, 3 Months After Hospital Discharge

\begin{tabular}{|c|c|c|c|}
\hline & Training & Control & $P$ \\
\hline \multicolumn{4}{|l|}{ Initial visit } \\
\hline ARB-II & 32.4 & 24.7 & .033 \\
\hline ACEI or ARB-II & 88.1 & 87.7 & .882 \\
\hline Digoxin & 22 & 26.3 & .21 \\
\hline Statins & 53.1 & 57.1 & .315 \\
\hline Anticoagulants & 40.9 & 40.3 & .874 \\
\hline Anti-platelet aggregators & 52.8 & 52.6 & .953 \\
\hline Diuretics & 86.2 & 89.6 & .187 \\
\hline Aldosterone antagonists & 36.5 & 34.4 & .59 \\
\hline \multicolumn{4}{|l|}{ Final visit } \\
\hline Beta-blockers & 92.5 & 88.4 & .089 \\
\hline Statins & 55.2 & 56.3 & .345 \\
\hline Anticoagulants & 41.2 & 41.7 & .896 \\
\hline Anti-platelet aggregators & 51.7 & 52.6 & .951 \\
\hline Diuretics & 82.4 & 86.1 & .221 \\
\hline Aldosterone antagonists & 38.0 & 31.6 & .107 \\
\hline
\end{tabular}

AACEI indicates angiotensin-converting enzyme inhibitor; ARB-II, angiotensin II receptor blockers

Results are expressed in percentages. There were no significant differences between the initial and the final visit in the percentage of patients who received each of the drugs.

\section{Evolution of the Pharmacologic Therapy During Follow-up}

No differences were detected at the final 3-month visit in the percentage of patients who received the various medications (Table 2). Nor were significant differences found between the percentage of patients who continued receiving each of the drugs at the final 3-month visit as compared with the first visit (Table 2). Beta-blockers were withdrawn in $6.8 \%$ of the intervention group patients and in $7.1 \%$ of the control group patients $(P=.97$, with no statistical significance [NS]). In all cases the reason for withdrawal was the onset of a severe side effect (hypotension or symptomatic bradycardia), with no differences between the 2 groups. The incidence of severe side effects was $9.8 \%$ in the intervention group and $9.5 \%$ in the control group $(P=.91, \mathrm{NS})$. The most usual side effect was symptomatic hypotension $(4.7 \%$ and $4.4 \%$, respectively). There were no differences between the 2 groups in the beta-blocker used. The doses of the 3 drugs on hospital discharge and at the final 3-month visit for the whole series are shown in Figure 1. At the final visit, the mean dose of the 3 beta-blockers increased significantly as compared with the initial visit. Comparison between the 2 groups of the dose of the 3 beta-blockers 3 months after discharge showed that the mean dose of the 3 drugs was significantly higher in the intervention group compared with the control group: bisoprolol, $5.91(0.84)$ versus $4.21(0.76) \mathrm{mg} / \mathrm{d}(\mathrm{P}<.01)$; nebivolol, $5.33(0.81)$ versus $4.07(0.68) \mathrm{mg} / \mathrm{d}(P<.01)$; and carvedilol, $30.21(4.26)$ versus $23.37(4.12) \mathrm{mg} / \mathrm{d}(P<.001)$ (Figure 2 ). The maximum beta-blocker dose was reached in $25 \%$ of the intervention group patients and $19 \%$ of the control group $(P=.098)$. The maximum dose or the maximum tolerated dose 3 months after hospital discharge was reached in $48 \%$ of the intervention group patients and $38 \%$ of the control group $(P=.014)$. 


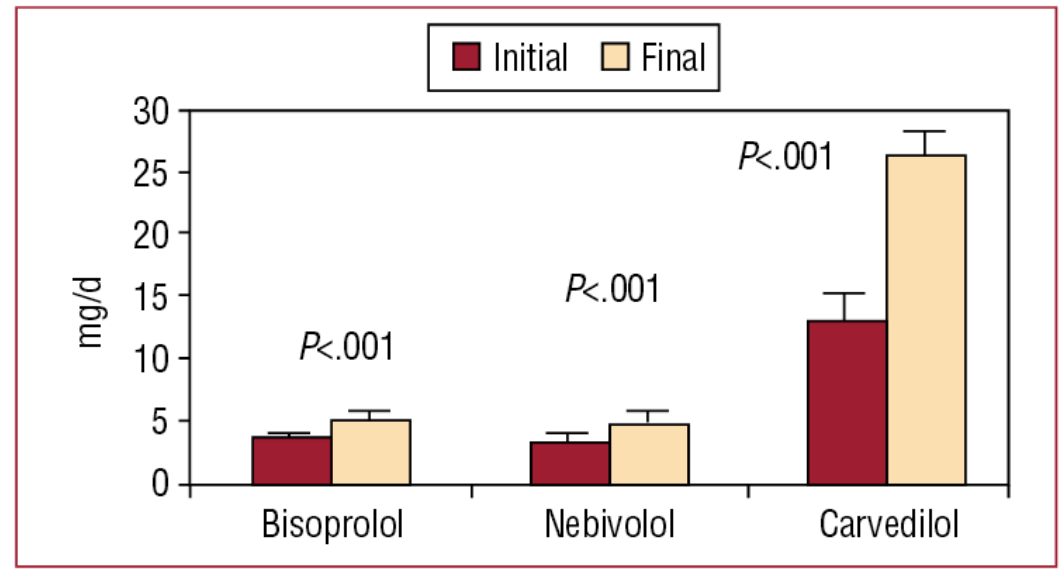

Figure 1. Mean dose of bisoprolol, nebivolol and carvedilol in the series of patients on hospital discharge (baseline visit) and at 3 months (final visit)

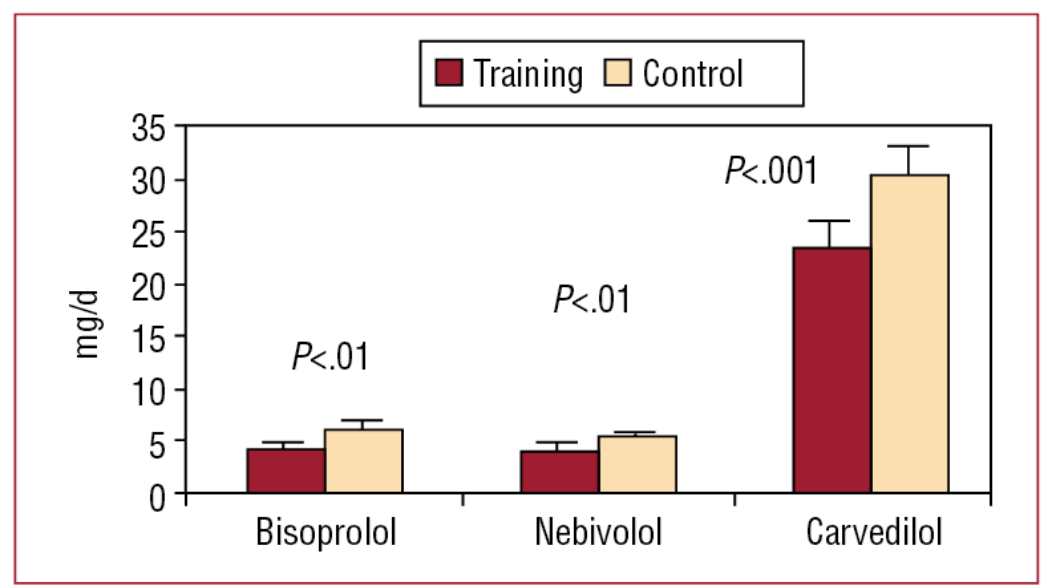

Figure 2. Mean dose of bisoprolol, nebivolol and carvedilol at the final visit in the intervention group and the control group.

\section{Events During the Follow-up}

There was a $16 \%$ reduction in the general incidence of cardiovascular events and $25 \%$ in the incidence of readmission for heart failure in the intervention group compared with the control group during the 3 months of follow-up (16\% vs $19 \%$ for total events and $9.2 \%$ vs $12.3 \%$ for admission due to heart failure, respectively), although these reductions were not statistically significant (Table 3). 
Table 3. Incidence of Events at 3 Months in the Training Group and the Control Group

\begin{tabular}{lccc}
\hline & Training & Control \\
\hline Total cardiovascular events & 16.4 & 18.9 & .422 \\
Readmission for CHF & 9.2 & 12.3 & .523 \\
Acute myocardial infarction & 1 & 1.1 & .976 \\
Unstable angina & 1.6 & 3 & .764 \\
Death & 3.3 & 2.3 & .783 \\
Stroke & 0.7 & 0.3 & .631 \\
Other & 2 & 1 & .593 \\
Days hospitalized & $8.7(7.4)$ & $8.2(8.1)$ & .769
\end{tabular}

CHF indicates chronic heart failure

Results are expressed in percentages (quantitative variables) and mean (standard deviation) (qualitative variables

\section{Predictors of Reaching the Maximum and/or the Maximum Tolerated Dose of Beta-Blockers}

The patients who, 3 months after hospital discharge, were receiving the maximum or the maximum tolerated dose of beta-blockers, in comparison with the other patients, had a history of less hypertension (72\% vs $81 \% ; P=.017)$ and less hypertensive etiology (35\% vs $46 \% ; P=.006)$, a higher prevalence of previous myocardial infarction ( $47 \%$ vs $38 \% ; P=.036)$ and ischemic etiology (58\% vs $49 \% ; P=.044)$, a lower ejection fraction (41 [12\%] vs $43[14 \%] ; P=.045)$ and higher brain natriuretic peptide (BNP) concentrations on admission (538 [304] vs 363 [292] pg/mL; $P=.042$ ) (Table 4). There were no differences between the 2 groups in the proportion of patients with an ejection fraction above or below $45 \%$. The multivariate analysis showed that being in the intervention group was an independent predictor for receiving the maximum or the maximum tolerated dose of beta-blockers at the 3-month visit (odds ratio $[\mathrm{OR}]=2.46 ; 95 \%$ confidence interval $[\mathrm{CI}], 1.29-4.69 ; \mathrm{P}=.0005$ ) (Table 5). Being in the intervention group was the most powerful independent predictor. 
Table 4. Patients Characteristics at the Initial Visit, by Achievement of the Maximum Dose and/or the Maximum Tolerated Dose of Beta-Blockers at 3 Months

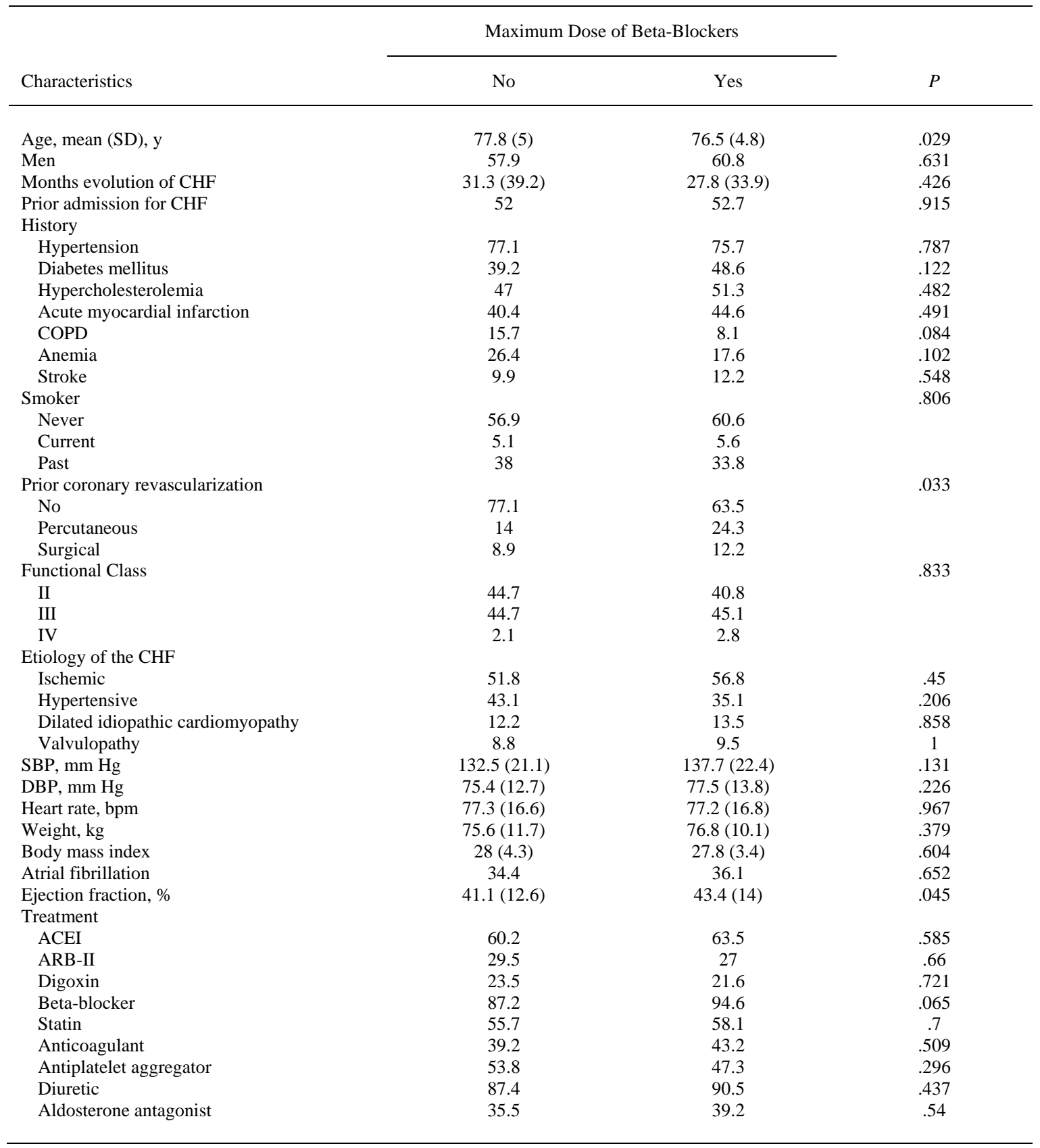

ACEI indicates angiotensin-converting enzyme inhibitor; ARB-II, angiotensin II receptor blocker; DBP, diastolic blood pressure; SBP, systolic blood pressure.

Results are expressed in percentages (quantitative variables) and mean (standard deviation) (qualitative variables) 
Table 5. Independent Predictors of Reaching the Maximum Dose and/or the Maximum Tolerated Dose of Beta-Blockers at 3 Months (Primary Study Aim)

\begin{tabular}{lccc}
\hline & OR & $95 \%$ CI \\
\hline & & & \\
Training group & 2.46 & $1.29-4.69$ & \\
Initial beta-blocker dose & 2.12 & $1.24-3.85$ & .0005 \\
Prior myocardial infarction & 1.24 & $1.09-1.67$ & .0015 \\
Serum sodium & 1.18 & $1.07-1.65$ & .025 \\
Age & 0.89 & $0.68-0.98$ & .035 \\
Ischemic etiology & 1.14 & $1.05-1.74$ & .045 \\
\end{tabular}

CI indicates confidence interval; OR, odds ratio.

\section{Discussion}

Beta-blockers are the drugs that most reduce mortality in patients with CHF (around 35\%).9-12However, the recommendations are not always fulfilled and an important percentage of patients fail to receive betablockers, or receive lower doses than recommended. Thus, measures specifically designed to disseminate the utility of beta-blockers, their regimens, recommended doses and management of the various problems they can cause may have a beneficial effect for patients with this problem. In our study, a simple training program given to a group of randomly selected primary care physicians about the use of beta-blockers in patients with heart failure shows it is possible to improve the management of beta-blockers by these physicians in patients aged 70 years or older recently discharged from hospital after being admitted for heart failure. The percentage of patients who received the maximum dose or the maximum tolerated dose was higher in the patients whose primary care physicians had been assigned to the intervention group as compared with a control group whose physician had not received the training program. Being in the intervention group was the most powerful independent predictor that the patient would receive the optimal beta-blocker dose 3 months after hospital discharge (OR=2.46; 95\% CI, 2.29-4.69; $\mathrm{P}=.0005)$. This was associated with a $16 \%$ reduction in the overall incidence of cardiovascular events and a $25 \%$ reduction in readmission for heart failure 3 months after discharge for the intervention group patients. However these reductions were not statistically significant, probably due to the low rate of associated events during the short follow-up period. It is important to note that our study only included patients who had no prior contraindication for the use of beta-blockers or who failed to tolerate them during their admission prior to hospital discharge, though this was only the case in less than $10 \%$ of all the hospitalized patients.

Although numerous reports have been published over recent years about intervention programs in heart failure, ${ }^{16-20}$ most were from hospital-based multidisciplinary units, coordinated by cardiologists and with specialized nursing personnel; only a few early efforts concerned strategies in the primary care setting. ${ }^{21,22}$ The recent OPTIMIZE-HF program showed that it is possible to improve the treatment, both pharmacologic and non-pharmacologic, and prognosis of CHF patients after hospital admission by adopting educational and training measures aimed at physicians and nurses, though again, basically in a hospital setting. ${ }^{23}$ This program confirmed that prescription of the adequate doses of beta-blockers was associated with a reduction in the rates of mortality and readmission due to heart failure, ${ }^{24}$ and that not stopping beta-blockers during hospitalization for decompensated CHF also produced lower rates of complications and mortality during hospitalization and after discharge. ${ }^{25}$ 


\section{Limitations}

This study has certain limitations, the main one being the short follow-up time of 3 months to evaluate the effect of the interventional training program on morbidity and mortality. This period was chosen as the main aim of our study to evaluate the influence of a simple, short training program about beta-blockers on the main outcome variable, which was the percentage of patients who were given the optimal dose of beta-blocker by their primary care physician; clinical practice guidelines recommend that the dose titration of these drugs should be done gradually over a period of 3 months to reduce the risk of adverse side effects. On the other hand, although beta-blockers are mainly recommended for patients with systolic CHF (depressed ejection fraction), most patients with $\mathrm{CHF}$ and preserved ejection fraction also receive these drugs, either for their bradycardial effect or to control hypertension and ischemic heart disease (the two main causes of this problem). In addition, the SENIORS study, which also included patients with $\mathrm{CHF}$ and preserved ejection fraction, showed that the effect of the beta-blockers was similar in patients with depressed or preserved ejection fraction. ${ }^{13}$ Accordingly, it was decided not to exclude patients with a preserved ejection fraction, although the training program given to the primary care physicians involved considerable discussion about these aspects.

\section{Conclusions}

The results of this study suggest that the use of beta-blockers in patients with CHF can be improved by simple training programs aimed at primary care physicians, as optimal doses were obtained in almost half the patients, and in a significantly greater proportion than in the control group patients; this intervention was the most powerful predictive factor of reaching the optimal dose of the drug. Beta-blockers can be safely used in this select group of older patients, who have no contraindication to their use, and in whom treatment is started by a cardiologist in the hospital. Although the short follow-up period of this study impeded reaching statistically significant results, the incidence of cardiovascular events and readmission for heart failure was reduced by $15 \%-25 \%$ at 3 months in the intervention group patients. Whether these results will persist over a longer time remains to be seen, and studies longer term are therefore required.

\section{Acknowledgments}

The authors wish to thank all the participating researchers for their work and effort, without which this study would not have been possible. Likewise, we wish to acknowledge the help provided by the staff at the Research Agency of the Spanish Society of Cardiology and Laboratorios Menarini, for their disinterested contribution to the project.

\section{Main researchers of the OBELICA study}

Álvarez Auñón, Amparo. Anguita Sánchez, Manuel. Arcos, Enrique de los. Arrarte Esteban, Vicente. Bardají Mayor, Juan Luis. Berrazueta Fernández, José R. Bertomeu Martínez, Vicente. Bierge Valero, David. Bover Freire, Ramón. Cabeza Láinez, Pedro. Castro Fernández, Antonio. Cremer, David. Fernández Lázaro, Luis Antonio. Fuente Galván, Luis de la. Fuertes Alonso, Jorge. García de Andoain, José María. García de la Villa, Bernardo. García González, Juan Pedro. García Quintana, Antonio. Giménez Cervantes, Diego. Gómez Barrado, José Javier. Gómez Belda, Ana B. González Juanatey, Carlos. González Llopis, Francisco. Guevara Zuazo, Justo. Hernández Alfonso, Julio. Hernández Fernández, Isidro. Iglesias Río, Enrique. Lozano Palencia, Teresa. Martín Santana, Antonio. Martínez Dolz, Luis. Matas González. Mayordomo López, Juan. Molina Laborda, Eduardo. Navarro Lostal, Carmen. Núñez Villota, Julio. Ortiz de Murúa, José Antonio. Pabón Osuna, Pedro. Pascual Figal, Domingo. Pastor Torres, Luis. Pérez de Juan, Miguel Ángel. Planas, Francesc. Quintas Ovejero, Laura. Río Ligorit, Alfonso del. Rodríguez García, Miguel Ángel. Rodríguez Padial, Luis. Roig Minguell, Eulalia. Romero Caballero, Dolores. Romero Menor, César. Roure Fernández, Julia. Ruiz-Valdepeñas, Luis. Sánchez Vega, Eugenio. Soto Priore, Adriana. 


\section{References}

1. M. Anguita Sánchez, M.G. Crespo Leiro, E. de Teresa Galván, M. Jiménez Navarro, L. Alonso-Pulpón, J. Muñiz García. Prevalencia de la insuficiencia cardiaca en la población general española mayor de 45 años. Estudio PRICE. Rev Esp Cardiol, 61 (2008), pp. 1041-1049.

2. D. Miani, C. Fresco, D. Lucci, M.C. Albanese, L. Gonzini, P.M. Fioretti, et al. Italian Survey on Acute Heart Failure Investigators Clinical characteristics, management, and prognosis of octogenarians with acute heart failure admitted to cardiology wards: results from the Italian Survey on Acute Heart Failure. Am Heart J, 158 (2009), pp. 126-132 42.

3. D.S. Lee, P. Gona, R.S. Vasan, M.G. Larson, E.J. Benjamin, T.J. Wang, et al. Relation of disease pathogenesis and risk factors to heart failure with preserved or reduced ejection fraction: insights from the framingham heart study of the national heart, lung, and blood institute. Circulation, 119 (2009), pp. 3070-3077.

4. The Task Force for the diagnosis and treatment of chronic heart failure of the European Society of Cardiology. Guidelines for the diagnosis and treatment of chronic heart failure: executive summary (update 2005). Eur Heart J, 26 (2005), pp. 1115-1140.

5. Hunt SA, Abraham WT, Chin MH, Feldman AM, Francis GS, Gamial TG, et al. ACC/AHA 2005 guidelines for the diagnosis and management of chronic heart failure in the adult. Available from: www.acc.org/clinical/guidelines/failure/ind.pdf.

6.. M. Komajda, P. Lapuerta, N. Hermans, J.R. González-Juanatey, D.J. van Veldhuisen, E. Erdmann, et al. Adherence to guidelines is a predictor of outcome in chronic heart failure: the MAHLER survey. Eur Heart J, 26 (2005), pp. 1653-1659.

7. K. MacIntyre, S. Capewell, S. Stewart, J.W.T. Chalmers, J. Boyd, A. Finlayson, et al. Evidence of improving prognosis in heart failure. Trends in case fatality in 66547 patients hospitalised between 1986 and 1995. Circulation, 102 (2000), pp. 1126-1131.

8. J.M. McMurray, A. Cohen-Solal, R. Dietz, E. Eichhorn, L. Erhardt, R. Hobbs, et al. Practical recommendations for the use of ACE inhibitors, betablockers and spironolactone in heart failure: putting guidelines into practice. Eur $\mathrm{J}$ Heart Fail, 3 (2001), pp. 495-502.

9.. M. Packer, M.R. Bristow, J.N. Cohn, W.S. Colucci, M.B. Fowler, E.M. Gilbert, et al. The effect of carvedilol on morbidity and mortality in patients with chronic heart failure. N Engl J Med, 334 (1996), pp. 1349-1355.

10.. M. Packer, A.J. Coats, M.B. Fowler, H.A. Katus, H. Krun, P. Mohacsi, For the COPERNICUS Study Group, et al. Effect of carvedilol on survival in sever chronic heart failure. N Engl J Med, 344 (2001), pp. 1651-1658.

11. MERIT-HF Study Group. Effect of metoprolol CR/XL in chronic heart failure: the MERIT-HF trial. Lancet, 353 (1999), pp. 2001-2007.

12. CIBIS II Investigators and Committees. The Cardiac Insufficiency Bisoprolol Study: a randomized trial. Lancet, 353 (1999), pp. 9-13.

13. M.D. Flather, M.C. Shibata, A.J.S. Coats, D.J. Van Veldhuisen, A. Parkhomenko, J. Borbola, On behalf of the SENIORS Investigators, et al. Randomized trial to determine the effect of nebivolol on mortality and cardiovascular hospital admission in elderly patients with heart failure (SENIORS). Eur Heart J, 26 (2005), pp. 215-225.

14. V. Barrios Alonso, G. Peña Pérez, J.R. González Juanatey, E. Alegría Ezquerra, J.V. Lozano Vidal, J.L. Llisterri Caro, et al. Hipertensión e insuficiencia cardiaca en consultas de atención primaria y cardiología en España. Rev Clin Esp, 203 (2003), p. 334.

15. P. Román-Sánchez, P. Conthe, J. García-Alegría, J. Forteza-Rey, M. Montero, C. Montoto. Factors influencing medical treatment of heart failure patients in Spanish internal medicine departments: a national survey. QJM, 98 (2005), pp. 127-138.

16. S. Ojeda, M. Anguita, M. Delgado, F. Atienza, C. Rus, A.L. Granados, et al. Short and long term results of a programme for the prevention of readmissions and mortality in patients with heart failure: are effects maintained after stopping the programme?. Eur J Heart Fail, 7 (2005), pp. 921-926.

17. A.D. Galbreath, R.A. Krasuski, B. Smith, K.C. Stajduhar, M.D. Kwan, R. Ellis, et al. Long term healthcare and cost outcomes of disease management in a large, randomised, community-based population with heart failure. Circulation, 110 (2004), pp. 1234-1243.

18. H.M. Krumholz, J. Amatruda, G.L. Smith, J.A. Mattera, S.A. Roumanis, M.J. Radford, et al. Randomized trial of an education and support Intervention to prevent readmission of patients with heart failure. J Am Coll Cardiol, 39 (2002), pp. 83-89.

19. E.K. Kasper, G. Gerstenblith, G. Hefter, E. van Anden, J.A. Brinker, D.R. Thiemann, et al. A randomized trial of the efficacy of multidisciplinary care in heart failure outpatients at high risk of hospital readmission. J Am Coll Cardiol, 39 (2002), pp. 471-480.

20. M. Anguita, Los investigadores del registro BADAPIC. Características clínicas, tratamiento y morbimortalidad a corto plazo de pacientes con insuficiencia cardiaca controlados en consultas específicas de insuficiencia cardiaca. Resultados del registro BADAPIC. Rev Esp Cardiol, 57 (2004), pp. 1159-1169.

21. M. Naylor, D. Brooten, R. Jones. Comprehensive discharge planning for the hospitalised elderly. Ann Intern Med, 120 (1994), pp. 999-1006.

22. M. Weinberger, E.Z. Oddone, W.G. Henderson, Fir the Veterans Affairs Cooperative Group on Primary Care and Hospital Readmissions. Does increased access to primary care reduce hospital readmissions?. N Engl J Med, 334 (1996), pp. 1441-1447. 
23. G.C. Fonarow, W.T. Abraham, N.M. Albert, W.G. Stough, M. Gheorghiade, B.H. Greemberg, et al. Influence of a performance-improvement initiative on quality of care for patients hospitalised with heart failure. Results of the OPTIMIZE-HF. Arch Intern Med, 167 (2007), pp. 1493-1502.

24. G.C. Fonarow, W.T. Abraham, N.M. Albert, W.G. Stough, M. Gheorghiade, B.H. Greemberg, et al. Prospective evaluation of betablocker use at the time of hospital discharge as a heart failure performance measure: results from OPTIMIZE-HF. J Card Fail, 13 (2007), pp. 722-731.

25. G.C. Fonarow, W.T. Abraham, N.M. Albert, W.G. Stough, M. Gheorghiade, B.H. Greemberg, et al. Influence of betablocker continuation or withdrawal on outcomes in patients hospitalised with heart failure. Findings from the OPTIMIZE-HF. J Am Coll Cardiol, 52 (2008), pp. 190-199. 